\title{
Perspectives on Professional Burnout and Occupational Stress among Medical Oncologists: A Cross-sectional Survey by Korean Society for Medical Oncology (KSMO)
}

\section{Yun-Gyoo Lee, MD, PhD 1 \\ Chi Hoon Maeng, MD, PhD² \\ Do Yeun Kim, MD, PhD ${ }^{3}$ \\ Bong-Seog Kim, MD, PhD"}

${ }^{1}$ Department of Internal Medicine, Kangbuk Samsung Hospital, Sungkyunkwan University School of Medicine, Seoul, ${ }^{2}$ Department of Internal Medicine, Kyung Hee University Hospital, Kyung Hee University College of Medicine, Seoul, ${ }^{3}$ Department of Internal Medicine, Dongguk University Ilsan Hospital, Goyang, ${ }^{4}$ Department of Internal Medicine, Veterans Health Service Medical Center, Seoul, Korea

Correspondence: Do Yeun Kim, MD, PhD Department of Internal Medicine, Dongguk University Ilsan Hospital, 27 Dongguk-ro, Ilsandong-gu, Goyang 10326, Korea

Tel: 82-31-961-7143

Fax: 82-31-961-7141

E-mail: kkamgdog@gmail.com

Co-correspondence: Bong-Seog Kim, MD, PhD Department of Internal Medicine,

Veterans Health Service Medical Center,

53 61-gil, Jinhwangdo-ro, Gangdong-gu,

Seoul 05368, Korea

Tel: 82-2-2225-1319

Fax: 82-2-740-4160

E-mail: seog9270@gmail.com

Received January 30, 2020

Accepted July 9, 2020

Published Online July 10, 2020

*Yun-Gyoo Lee and Chi Hoon Maeng contributed equally to this work.

\section{Purpose}

This study aimed to investigate the prevalence and risk factors of burnout and occupational stress among medical oncologists in Korea.

\section{Materials and Methods}

A survey was conducted of medical oncologists who were members of Korean Society for Medical Oncology (KSMO) using the Korean Occupational Stress Scale, the validated Maslach Burnout Inventory (MBI) and supplemental questions about work and lifestyle factors.

\section{Results}

Among 220 active KSMO members, 111 responses were collected. The median age was 42 years (range, 32 to 63 years). Two-thirds of responders worked 6 days per week and half of them worked a total of 60-80 hours per week. Each medical oncologist treated a median of 90-120 patients per week in outpatient clinics and 20-30 patients per week in patient practices. MBI subscales indicated a high level of emotional exhaustion in $74 \%$, a high level of depersonalization in $86 \%$, and a low level of personal accomplishment in $65 \%$ : $68 \%$ had professional burnout according to high emotional exhaustion and high depersonalization scores. The risk of burnout was higher for medical oncologists aged from 30-39 than 40-49 years, and unmarried than married. Considering personal accomplishment, females had a higher risk of burnout. The median score of occupational stress was 63 (range, 43 to 88). Having night-duty call was the strongest risk factor on more stress. A higher stress score was associated with a higher prevalence of burnout.

\section{Conclusion}

Burnout and occupational stress are quite common amongst Korean medical oncologists. Achieving a healthy work-life balance, ensuring balanced workload distribution, and engaging in proper stress relief solutions are necessary.

\section{Key words}

Burnout, Occupational stress, Medical oncologists

\section{Introduction}

A career in medical oncology is exceedingly rewarding. Fast-moving advances in research and therapeutics, intriguing dynamics in practice environments, and opportunities to provide critical support to patients are professionally appealing and satisfying [1]. Still, all of these characteristics place medical oncologists at high risk for stress. Therefore, medical oncologists have been the focus of concerns regarding stress.

Burnout is a psychosocial syndrome that involves prolonged response to chronic emotional and interpersonal stressors on the job [2]. Burnout is characterized by emotional exhaustion (EE), feelings of depersonalization (DP), and reduced personal accomplishment (PA) [2]. Physicians commonly suf- 
fer from distress due to burnout, with studies suggesting a prevalence of $32 \%$ among medical oncologists [3]. High mortality rates among patients with advanced cancer, increasing numbers of cancer patients, as well as changing practice migrating to more comprehensive care management solutions can trigger burnout in medical oncologists [4].

Since such stress and burnout can cause negative consequences related to professional satisfaction and personal life, as well as quality of patient care, this issue deserves attention [5]. Burnout and occupational stress have been extensively studied among oncologists in the United States and Europe $[6,7]$. However, little is known about the situation among Koreanmedical oncologists. Therefore, we conducted a nationwide survey to investigate the prevalence of professional burnout and occupational stress among Korean medical oncologists. Then we identified work and lifestyle factors that affect burnout and occupational stress.

\section{Materials and Methods}

\section{Participants}

Between May 2018 and June 2018, a cross-sectional, webbased survey of 220 medical oncologists who were active in the field was conducted through the Korean Society for Medical Oncology (KSMO). All responders were invited via an e-mail that included a link to the survey and fully informed of the overall purpose of our survey prior to participation. SurveyMonkey (https:// ko.surveymonkey.com) was used to build the web-based online survey. All authors as the committee members of the KSMO Insurance and Policy Committee supervised the entire investigation, ensured the reliability of the data and analyzed the results.

\section{Study measures}

The survey consisted of three parts with a total of 73 questions: personal and professional characteristics (27 questions), occupational stress (24 questions), and burnout (22 questions). The initial 26 questions consisted of two questions regarding demographics, 12 regarding occupational environment, and 13 regarding a pattern of living. Among 13 questions for lifestyle, the respondents were asked to rate their job satisfaction on a scale of 100 and asked if they were balanced in their work and life.

Occupational stress was assessed by the Korean Occupational Stress Scale (KOSS) [8]. Job stress should be investigated in the local and cultural context of each worker, and KOSS is a validated self-reported questionnaire that examines job stress and reflects the organizational culture of Korea. The KOSS short-form (KOSS-SF), which was used in this study, is an abbreviated survey designed to be used at work place settings [9]. It consists of seven subscales (24 items total): job demand (4 items), insufficient job control (4 items), interper- sonal conflict ( 3 items), job insecurity (2 items), occupational system (4 items), lack of reward ( 3 items), and organizational climate (4 items).

Burnout was estimated using the validated Maslach Burnout Inventory-Human Service Survey (MBI-HSS) [10]. The MBI-HSS consists of 22 questions to evaluate three domains of burnout: EE (9 questions), feelings of DP (5 questions), and reduced PA (8 questions). Each question was scored on a 7-point frequency rating from ' 0 ' (never) to ' 6 ' (every day). The sum of raw scores was assessed for the presence of burnout: a score of 27 or higher on the EE subscale, 10 or higher on the DP subscale, or lower than 33 on the PA subscale was considered to indicate a high level of burnout $[2,11]$. In this study, MBI-HSS which was translated into Korean and validated for university hospital workers in Korea was used. The cutoff values in three domains in burnout were also verified [12]. To define burnout in a conventional approach, medical oncologists with high DP and EE, and low PA subscale scores were considered to have professional burnout [13]. The next predominant definition of burnout (high DP and EE) was also used.

\section{Statistical analysis}

The questionnaires completed by June 2018 were included for further analyses. To compare the characteristics of the study participants between the groups, we used independent $t$ tests for continuous variables and Fisher exact tests or chi-square tests for categorical variables. To analyze the risk factors for professional burnout, multivariate logistic regression analyses were performed. To analyze the relationship between risk factor and occupational stress, linear regression analyses were performed. All statistical analyses were performed by STATA ver. 13.0 software (StataCorp LP, College Station, TX).

\section{Ethical statement}

This study complied with the Declaration of Helsinki and was conducted under Institutional Review Board (IRB) approval at the Veterans Health Service Medical Center (IRB No. 2108-04-033). Participation in this survey was regarded as agreeing to the study, so written informed or verbal consent requirements from respondents were waived. All data were de-identified.

\section{Results}

\section{Personal and professional characteristics}

An e-mail invitation was sent to 220 active medical oncologists and 175 responses (80\%) were received. There were 64 incomplete questionnaires, and complete responses from 111 participant $(51 \%)$ were included in the final analysis.

Personal and professional characteristics of participants 
Table 1. Personal and professional characteristics of participating medical oncologists $(\mathrm{n}=111)$

\begin{tabular}{|c|c|}
\hline Characteristic & No. (\%) \\
\hline \multicolumn{2}{|l|}{ Sex } \\
\hline Male & $62(55.8)$ \\
\hline Female & $49(44.1)$ \\
\hline \multicolumn{2}{|l|}{ Age (yr) } \\
\hline Median (range) & $42(32-63)$ \\
\hline$\leq 39$ & $38(34.2)$ \\
\hline $40-49$ & $58(52.2)$ \\
\hline$\geq 50$ & $15(13.5)$ \\
\hline \multicolumn{2}{|l|}{ Relationship status } \\
\hline Married & $92(82.9)$ \\
\hline Single & $19(17.1)$ \\
\hline \multicolumn{2}{|l|}{ Religious: yes vs. no } \\
\hline Yes & $64(57.7)$ \\
\hline No & $47(42.3)$ \\
\hline \multicolumn{2}{|l|}{ Drinking habit } \\
\hline$\leq 1$ drink per month & $40(36.0)$ \\
\hline 2-4 drinks per month & $55(49.5)$ \\
\hline$\geq 2-3$ drinks per week & $16(14.4)$ \\
\hline \multicolumn{2}{|l|}{ Exercise per week } \\
\hline Never & $49(44.1)$ \\
\hline 1-2 days & $43(38.7)$ \\
\hline 3-5 days & $17(15.3)$ \\
\hline Every day & $2(1.8)$ \\
\hline \multicolumn{2}{|l|}{ Type of hospital } \\
\hline Superior general hospital & $68(61.3)$ \\
\hline General hospital & $37(33.3)$ \\
\hline Public hospital & $6(5.4)$ \\
\hline \multicolumn{2}{|c|}{ Faculties in medical oncology, number } \\
\hline Median (range) & $5(1-16)$ \\
\hline In-house hospitalists (yes) & $36(32.4)$ \\
\hline Daytime primary on-call (yes) & $30(27.0)$ \\
\hline Nights on-call (yes) & $16(14.4)$ \\
\hline Saturday duty (yes) & $73(65.8)$ \\
\hline For outpatient clinic & $12(10.8)$ \\
\hline For inpatient rounding & $45(40.5)$ \\
\hline For outpatient and inpatient & $16(14.4)$ \\
\hline \multicolumn{2}{|c|}{$\begin{array}{l}\text { Work hours per week (includes patient care, } \\
\text { administrative work, research, and teaching) }\end{array}$} \\
\hline$<40$ & $1(0.9)$ \\
\hline $40-60$ & $35(31.5)$ \\
\hline $60-80$ & $45(40.5)$ \\
\hline $80-100$ & $18(16.2)$ \\
\hline$>100$ & $12(10.8)$ \\
\hline \multicolumn{2}{|c|}{ Outpatients seen in clinic every week } \\
\hline $30-60$ & $20(18.0)$ \\
\hline $60-90$ & $26(23.4)$ \\
\hline $90-120$ & $25(22.5)$ \\
\hline $120-150$ & $16(14.4)$ \\
\hline$>150$ & $24(21.6)$ \\
\hline
\end{tabular}

(Continued)
Table 1. Continued

\begin{tabular}{lc} 
Characteristic & No. $(\%)$ \\
$\begin{array}{l}\text { Inpatients seen in hospital every week } \\
<10\end{array}$ & $11(9.9)$ \\
$10-20$ & $53(47.7)$ \\
$20-30$ & $26(23.4)$ \\
$>30$ & $21(18.9)$ \\
Overall job satisfaction (0-100 scale) & \\
$\quad$ Mean \pm SD & $54.8 \pm 21.8$ \\
Median (range) & $50(0-100)$ \\
\hline
\end{tabular}

Table 2. Prevalence of burnout and occupational stress among medical oncologists $(\mathrm{n}=111)$

\begin{tabular}{|c|c|}
\hline Characteristic & Score \\
\hline \multicolumn{2}{|l|}{ Burnout indices } \\
\hline \multicolumn{2}{|l|}{ Emotional exhaustion (EE) } \\
\hline Mean \pm SD & $33.3 \pm 9.7$ \\
\hline Median (range) & $34(8-54)$ \\
\hline High degree of burnout, sum $\geq 27, \mathrm{n}(\%)$ & $82(73.9)$ \\
\hline \multicolumn{2}{|l|}{ Depersonalization (DP) } \\
\hline Mean \pm SD & $15.2 \pm 5.9$ \\
\hline Median (range) & $14(0-27)$ \\
\hline High degree of burnout, sum $\geq 10, \mathrm{n}(\%)$ & $96(86.5)$ \\
\hline \multicolumn{2}{|l|}{ Personal accomplishment (PA) } \\
\hline Mean \pm SD & $31.3 \pm 5.4$ \\
\hline Median (range) & $30(19-42)$ \\
\hline High degree of burnout, sum $\leq 33, \mathrm{n}(\%)$ & $72(64.9)$ \\
\hline \multicolumn{2}{|l|}{ Overall professional burnout, n (\%) } \\
\hline High EE and DP scores & $76(68.4)$ \\
\hline High EE and DP, and low PA & $54(48.6)$ \\
\hline \multicolumn{2}{|l|}{ Occupational stress } \\
\hline Mean \pm SD & $61.7 \pm 7.8$ \\
\hline Median (range) & $63(43-88)$ \\
\hline
\end{tabular}

are summarized in Table 1 . Men were $56 \%$ of participants. A median age of participants was 42 years old. Of the responders, $83 \%$ were married and 58\% practiced a religion. As for drinking habits, $34 \%$ of participants reported they rarely drink (less than one drink a month), 50\% reported that they drink sometimes (two-four drinks a month), the others (14\%) reported they drink frequently (more than two-three drinks a week). As for exercise habits, approximately $44 \%$ of participants responded that they never exercise at all and only $2 \%$ responded that they exercise every day.

Most participants were working in tertiary care hospitals $(61 \%)$ and general hospitals $(33 \%)$. The median number of accompanying faculty in medical oncology was five persons. Roughly one-third of participants (32\%) were working in institutions with in-house hospitalists. Only $11 \%$ of participants were in a single-organ specialty practice, and the others served in multi-organ specialty practice. Participants 
Table 3. The relationship between professional burnout, occupational stress, and job satisfaction

\begin{tabular}{|c|c|c|c|c|}
\hline \multirow{2}{*}{ Burnout } & \multicolumn{2}{|c|}{ Occupational stress } & \multicolumn{2}{|c|}{ Job satisfaction } \\
\hline & Score & p-value ${ }^{a)}$ & Score & p-value ${ }^{a)}$ \\
\hline \multicolumn{5}{|c|}{ High EE and DP scores } \\
\hline No burnout & $56.9 \pm 7.4$ & $<0.001$ & $66.3 \pm 2.1$ & $<0.001$ \\
\hline Burnout & $63.9 \pm 6.9$ & & $49.5 \pm 2.0$ & \\
\hline \multicolumn{5}{|c|}{ High EE and DP, and low PA } \\
\hline No burnout & $59.0 \pm 7.3$ & $<0.001$ & $63.9 \pm 2.0$ & $<0.001$ \\
\hline Burnout & $64.5 \pm 7.2$ & & $45.2 \pm 1.9$ & \\
\hline
\end{tabular}

Values are presented as mean \pm standard deviation. EE, emotional exhaustion; DP, depersonalization; PA, personal accomplishment. ${ }^{a)} \mathrm{p}$-value was derived from independent $\mathrm{t}$ test to compare mean values between two groups.

treated a median of three types of cancer. About one-quarter of participants had daytime primary call, and $14.0 \%$ received night emergency calls instead of residents. Two-thirds of participants responded that they work 6 days a week, including Saturday. Participants spent an average of 60 to 80 hours each week devoted to professional activities, including patient care, administrative work, research, and teaching. On average, participants cared for 90 to 120 patients in the outpatient setting each week and 20 to 30 patients in the inpatient setting. The mean overall job satisfaction score was 54.8.

\section{Prevalence of burnout, and its relationship with occupa- tional stress and job satisfaction}

The prevalence of burnout and occupational stress among participating medical oncologists is presented in Table 2. In all, $74 \%$ of participants experienced a high degree of $\mathrm{EE}, 87 \%$ experienced a high level of DP, and $65 \%$ had a low sense of PA. In aggregate, 76 (68\%) medical oncologists had professional burnout according to high EE and high DP scores. On a more conservative basis (high EE and high DP, and low $\mathrm{PA})$, about half $(49 \%)$ of medical oncologists were found to have burnout.

The mean occupational stress score was 61.7 (range 43 to 88). We investigated the relationship between professional burnout and occupational stress, and job satisfaction (Table 3). The participants with burnout showed a higher occupational stress score than those without burnout $(p<0.001)$. The participants with burnout showed a lower job satisfaction score than those without burnout $(p<0.001)$. Only 27\% of medical oncologists reported that they maintained worklife balance well.

Predictors that were significantly associated with burnout or occupational stress on multivariate analysis are listed in Tables 4 and 5. The risk of burnout was higher for medical oncologists aged from 30 to 39 years than those aged 40 to 49 years. Unmarried persons had a higher risk of burnout than married persons. After consideration of PA score, females had a higher risk of burnout than males.

For risk factors on occupational stress, there was a strong relationship between having night-duty call and high occupational stress score $(\mathrm{p}=0.001)$.

In this survey, multiple answer choices were accepted for the question related to causes of stress. In all, 78\% of participants stated that the biggest cause of burnout or occupational stress was the enforcement of the Act for the Improvement of Training Conditions and Status of Medical Residents, which limits maximum weekly hours of work for residents to 80 . Other major causes of burnout or occupational stress included a lack of residents in the department of internal medicine $(52 \%)$, increased administrative and clinical workloads required by the Life-Sustaining Treatment Decision-Making Act $(44 \%)$, and responsibilities of daytime primary call (23\%).

\section{Discussion}

The phenomenon of burnout is caused by frequent exposure to chronic occupational stress and is characterized by a 3-dimensional syndrome comprised of EE, DP (also known as cynicism), and reduced PA [12]. Physician's burnout is particularly dangerous and should be avoided, since it can increase medical errors and reduce quality of care for patients [13-15]. The nature of practicing oncology is changing. An increment of workload by expansion in patient volume, burdensomeness of administrative tasks, and complexity of innovative oncology place medical oncologists at increasing risk of stress and subsequent burnout [16]. Burnout can be overcome by investigating work environments and identifying underlying problems [17].

In line with these environments, we conducted the first large-scale nationwide study of Korean medical oncologists using standardized instruments toevaluateburnout and occupational stress. Overall, 68\% of Korean medical oncologists were burned out according to the high EE and DP domains at the time of the survey, which was higher than the $44.7 \%$ of U.S. oncologists and the $51 \%$ of Chinese oncologists reported in previous studies $[18,19]$. Our result was similar to the $71 \%$ burnout rate reported by study in European countries 
Table 4. Multivariate analysis for burnout related to personal and professional factors

\begin{tabular}{|c|c|c|c|c|c|c|c|c|}
\hline \multirow{3}{*}{ Characteristic } & \multicolumn{8}{|c|}{ Odds ratio (p-value) } \\
\hline & \multicolumn{4}{|c|}{ Burnout (high EE and DP) } & \multicolumn{4}{|c|}{ Burnout (high EE and DP, and low PA) } \\
\hline & Univariate & p-value & Multivariate & p-value & Univariate & p-value & Multivariate & p-value \\
\hline \multicolumn{9}{|l|}{ Sex } \\
\hline Male & 1 & & - & & 1 & & 1 & \\
\hline Female & 2.63 & 0.027 & - & - & 2.92 & 0.007 & 2.87 & 0.011 \\
\hline \multicolumn{9}{|l|}{ Age group (yr) } \\
\hline$\leq 39$ & 1 & & 1 & & 1 & & 1 & \\
\hline $40-49$ & 0.38 & 0.069 & 0.20 & 0.012 & 0.54 & 0.154 & 0.13 & 0.012 \\
\hline$\geq 50$ & 0.09 & 0.001 & - & - & 0.09 & 0.004 & - & - \\
\hline \multicolumn{9}{|l|}{ Relationship status } \\
\hline Single & 1 & & 1 & & 1 & & - & \\
\hline Married & 0.09 & 0.025 & 0.10 & 0.030 & 0.37 & 0.064 & - & - \\
\hline \multicolumn{9}{|l|}{ Religion } \\
\hline No & 1 & & - & & 1 & & - & \\
\hline Yes & 0.61 & 0.246 & - & - & 0.85 & 0.663 & - & - \\
\hline \multicolumn{9}{|l|}{ Drinking habit } \\
\hline$\leq 1$ per month & 1 & & - & & 1 & & - & \\
\hline 2-4 per month & 1.13 & 0.784 & - & - & 1.16 & 0.724 & - & - \\
\hline$\geq 2-3$ per week & 1.56 & 0.506 & - & - & 1.16 & 0.804 & - & - \\
\hline \multicolumn{9}{|l|}{ Exercise } \\
\hline Never & 1 & & - & & 1 & & - & \\
\hline 1-2 days per week & 1.02 & 0.969 & - & - & 0.55 & 0.152 & - & - \\
\hline 3-7 days per week & 0.76 & 0.623 & - & - & 0.32 & 0.046 & - & - \\
\hline \multicolumn{9}{|l|}{ Type of hospital } \\
\hline Superior general & 1 & & - & & 1 & & - & \\
\hline General & 0.57 & 0.190 & - & - & 0.81 & 0.604 & - & - \\
\hline Public & 1.94 & 0.557 & - & - & 5.30 & 0.137 & - & - \\
\hline \multicolumn{9}{|l|}{ Daytime on-call } \\
\hline No & 1 & & - & & 1 & & - & \\
\hline Yes & 1.74 & 0.261 & - & - & 1.08 & 0.862 & - & - \\
\hline \multicolumn{9}{|l|}{ Nights on-call } \\
\hline No & 1 & & 1 & & 1 & & - & \\
\hline Yes & 8.36 & 0.044 & 8.46 & 0.049 & 1.43 & 0.512 & - & - \\
\hline \multicolumn{9}{|l|}{ Saturday duty } \\
\hline No & 1 & & - & & 1 & & - & \\
\hline Yes & 1.21 & 0.661 & - & - & 1.49 & 0.321 & - & - \\
\hline \multicolumn{9}{|l|}{ Work hours per week } \\
\hline$<60$ & 1 & & - & & 1 & & - & \\
\hline $60-80$ & 1.76 & 0.232 & - & - & 0.875 & 0.765 & - & - \\
\hline $80-100$ & 1.43 & 0.555 & - & - & 1 & $>0.99$ & - & - \\
\hline$>100$ & 7.86 & 0.060 & - & - & 1 & $>0.99$ & - & - \\
\hline
\end{tabular}

EE, emotional exhaustion; DP, depersonalization; PA, personal accomplishment.

that focused on young ( $\leq 40$ years old) oncologists. Among personal characteristics, younger age (30-39 years vs. 40-49 years), being unmarried, and working night duty were independently associated with a high risk of professional burnout. Younger age, as well as being early in their careers, are well-known demographic risk factors for burnout of physicians in many medical departments [17]. In general, young people often take on a variety of administrative tasks in addition to clinical workloads. Additionally, physicians who are in early career stages must spend time not only on patient care but also on research and education.

Interestingly, when we consider more conservative definition of burnout including low PA (high EE and DP, and low PA), female gender was significantly associated with a high 
Table 5. Multivariate analysis for occupational stress related to personal and professional factors

\begin{tabular}{|c|c|c|c|c|}
\hline \multirow{3}{*}{ Characteristic } & \multicolumn{4}{|c|}{ Occupational stress } \\
\hline & \multicolumn{2}{|c|}{ Univariate } & \multicolumn{2}{|c|}{ Multivariate } \\
\hline & Coefficient & p-value & Coefficient & p-value \\
\hline \multicolumn{5}{|l|}{ Sex } \\
\hline Male & 1 & & - & \\
\hline Female & 2.44 & 0.099 & - & - \\
\hline \multicolumn{5}{|l|}{ Age group (yr) } \\
\hline$\leq 39$ & 1 & & - & \\
\hline $40-49$ & -1.48 & 0.161 & - & - \\
\hline$\geq 50$ & -3.68 & 0.122 & - & - \\
\hline \multicolumn{5}{|l|}{ Relationship status } \\
\hline Single & 1 & & - & \\
\hline Married & -2.11 & 0.283 & - & - \\
\hline \multicolumn{5}{|l|}{ Religion } \\
\hline No & 1 & & - & \\
\hline Yes & -2.11 & 0.157 & - & - \\
\hline \multicolumn{5}{|l|}{ Drinking habit } \\
\hline$\leq 1$ per month & 1 & & - & \\
\hline 2-4 per month & -1.25 & 0.438 & - & - \\
\hline$\geq 2-3$ per week & -3.11 & 0.177 & - & - \\
\hline \multicolumn{5}{|l|}{ Exercise } \\
\hline Never & 1 & & - & \\
\hline 1-2 days per week & -0.22 & 0.894 & - & - \\
\hline 3-7 days per week & -2.00 & 0.345 & - & - \\
\hline \multicolumn{5}{|l|}{ Type of hospital } \\
\hline Superior general & 1 & & - & \\
\hline General & -2.37 & 0.136 & - & - \\
\hline Public & 2.33 & 0.480 & - & - \\
\hline \multicolumn{5}{|l|}{ Daytime on-call } \\
\hline No & 1 & & - & \\
\hline Yes & 2.32 & 0.163 & - & - \\
\hline \multicolumn{5}{|l|}{ Nights on-call } \\
\hline No & 1 & & 1 & \\
\hline Yes & 6.44 & 0.002 & 6.44 & 0.001 \\
\hline \multicolumn{5}{|l|}{ Saturday duty } \\
\hline No & 1 & & - & \\
\hline Yes & 0.23 & 0.884 & - & - \\
\hline \multicolumn{5}{|l|}{ Work hours per week } \\
\hline$<60$ & 1 & & - & \\
\hline $60-80$ & -1.72 & 0.318 & - & - \\
\hline $80-100$ & 0.75 & 0.735 & - & - \\
\hline$>100$ & 4.11 & 0.110 & - & - \\
\hline
\end{tabular}

risk of burnout. Analysis that female gender was a risk factor of burnout has been reported in previous studies [20-22]. Rath et al. [21] reported a large study on burnout for gynecologic oncologists that female gender was also identified as risk factor for burnout. In another study for surgeons, more women than men surgeons had burnout and depressive symptoms [22]. In that study, work-home conflicts accounted for a major contributor to surgeon burnout, especially to female surgeon. Although we did not measure work-home conflicts in our survey, our results could be interpreted that women medical oncologists are under more pressure in terms of personal achievement probably from work-home conflicts.

Yeob et al. [20] conducted a similar nationwide survey recruiting a total of 130 medical, surgical, and radiation oncologists from 13 cancer centers in Korea. That study found that 
female gender and long working hours were associated with increased risks of burnout, which was consistent finding of our study. To evaluate burnout, unlike our study, they used Professional Quality of Life scale, which was developed to measure the quality of life of health care professionals [23]. Although burnout is a domain of the Professional Quality of Life Scale described above, MBI-HSS is appreciated a more reliable and valid measure of burnout [24].

One of the biggest reasons for burnout or occupational stress reported in our survey-chosen by $78 \%$ of participants-was the enforcement of the Act for the Improvement of Training Conditions and Status of Medical Residents, which limits residents to a maximum of 80 work hours per week. Although the working time of residents has been substantially reduced due to the enactment of the law, many hospitals were not equipped with alternative personnel such as a hospitalist (only $32 \%$ of participants were working with in-house hospitalists). It caused a significant increase in faculty's workload.

Our study showed that medical oncologists who felt burnout had a high level of occupational stress and a low level of job satisfaction (Table 3). According to a recent global survey of job satisfaction among medical oncologists [25], younger age and fewer years in clinical practice were associated with low job satisfaction. Interestingly, that study showed that medical oncologists with low job satisfaction tended to have fewer conversations with patients about disease prognosis, suggesting that low job satisfaction is also associated with low quality of patient care. In other words, burnout, low job satisfaction, and low quality of patient care correlate with each other, and one may be the cause and/or effect of the other.

There have been many reports of interventions to decrease physician burnout. Interventions that focus on individual physicians include intensive face-to-face workshops [26], communication skills training [27], stress management skills training [28], and mindfulness-based stress reduction programs [5]. Such interventions have been reported to help relieve stress, but these programs are not readily applicable or available to each oncologist. Even without formal programs, one of the easiest things is exercise. In our study, only half of the participants exercised. Exercise is known to have the potential to be effective for burnout prevention, so even in harsh clinical works, it is recommended to encourage medical oncologists to engage in regular exercise programs [29]. One study suggested the idea that enhancing professionalism can lower burnout [30]. Professionalism is often used to describe behavioral and value standards of performance that any professional is expected to achieve in their work, and knowledge that professionals need to perform their job efficiently. It is necessary to improve professionalism by reinforcement of expertise and applied rewards.
Still, one report suggested that organizational or systemlevel interventions are much more effective for controlling burnout than individual efforts [31]. Organization-directed strategies are mostly related to changes in work shift schedules, but oncologist-specific system-level methods have not been studied [31]. Therefore, the system-level strategies for management of Korean medical oncologists are warranted [32].

Our study has some limitations. First, there is considerable variation across studies regarding cutoff scores for burnout among healthcare professionals [33]. According to Maslach guidelines, more conservative definitions (the combination of high EE, high DP, and low PA) have been widely used $[2,33]$. However, this definition risks underestimating the burnout rate. In our study, we followed the recent consensus that defined burnout as high EE and high DP [11,18,34]. Based on our further analyses (Tables 3 and 4), the difference between the two definitions did not show a significant difference in the results except for prevalence. Second, our study participants were younger than those in previous surveys. Additionally, only $51 \%$ of potential participants (active medical oncologists) responded to this survey. These factors may have resulted in selection and response bias. However, our study is the first large-scale national study only for Korean medical oncologists registered to a major association (i.e., KSMO). Therefore, the results of our study are representative of a major population of medical oncology professionals in Korea. Third, our survey did not recruit other experts from different disciplines such as surgical and radiation oncologists. Because multidisciplinary team approach is essential in the management of advanced cancer, a follow-up study including all key professionals is warranted to make this burnout study more practical.

A considerable number of medical oncologists in Korea are burning out with a high level of occupational stress and lower job satisfaction. In order to provide the high quality of cancer care to cancer patients, further efforts should be conducted to find out the way to relieve the burnout and occupational stress of Korean medical oncologists from point of view of system-level management plan as well as individual effort.

\section{Conflicts of Interest}

Conflicts of interest relevant to this article was not reported.

\section{Acknowledgments}

This study was supported for administrative assistance by KSMO. 


\section{References}

1. Shanafelt T, Dyrbye L. Oncologist burnout: causes, consequences, and responses. J Clin Oncol. 2012;30:1235-41.

2. Maslach C, Schaufeli WB, Leiter MP. Job burnout. Annu Rev Psychol. 2001;52:397-422.

3. Medisauskaite A, Kamau C. Prevalence of oncologists in distress: systematic review and meta-analysis. Psychooncology. 2017;26:1732-40.

4. Jung KW, Won YJ, Kong HJ, Lee ES. Prediction of cancer incidence and mortality in Korea, 2018. Cancer Res Treat. 2018;50: 317-23.

5. Amutio A, Martinez-Taboada C, Delgado LC, Hermosilla D, Mozaz MJ. Acceptability and effectiveness of a long-term educational intervention to reduce physicians' stress-related conditions. J Contin Educ Health Prof. 2015;35:255-60.

6. Shanafelt TD, Raymond M, Kosty M, Satele D, Horn L, Pippen $\mathrm{J}$, et al. Satisfaction with work-life balance and the career and retirement plans of US oncologists. J Clin Oncol. 2014;32:112735.

7. Banerjee S, Califano R, Corral J, de Azambuja E, De MattosArruda L, Guarneri V, et al. Professional burnout in European young oncologists: results of the European Society for Medical Oncology (ESMO) Young Oncologists Committee Burnout Survey. Ann Oncol. 2017;28:1590-6.

8. Shin HC. Measuring stress with questionnaires. J Korean Med Assoc. 2013;56:485-95.

9. Park SG, Min KB, Chang SJ, Kim HC, Min JY. Job stress and depressive symptoms among Korean employees: the effects of culture on work. Int Arch Occup Environ Health. 2009;82:397405.

10. Maslach C, Jackson SE, Leiter MP. Maslach burnout inventory manual. Palo Alto, CA: Consulting Psychologists Press; 1996.

11. Shanafelt TD, Boone S, Tan L, Dyrbye LN, Sotile W, Satele D, et al. Burnout and satisfaction with work-life balance among US physicians relative to the general US population. Arch Intern Med. 2012;172:1377-85.

12. Bianchi R, Schonfeld IS, Laurent E. Burnout-depression overlap: a review. Clin Psychol Rev. 2015;36:28-41.

13. Wallace JE, Lemaire JB, Ghali WA. Physician wellness: a missing quality indicator. Lancet. 2009;374:1714-21.

14. Fahrenkopf AM, Sectish TC, Barger LK, Sharek PJ, Lewin D, Chiang VW, et al. Rates of medication errors among depressed and burnt out residents: prospective cohort study. BMJ. 2008;336:488-91.

15. Shanafelt TD, Balch CM, Bechamps G, Russell T, Dyrbye L, Satele D, et al. Burnout and medical errors among American surgeons. Ann Surg. 2010;251:995-1000.

16. Genentech. The 2018 Genentech oncology trend report. 10th ed. South San Francisco, CA: Genentech; 2018.

17. Murali K, Makker V, Lynch J, Banerjee S. From burnout to resilience: an update for oncologists. Am Soc Clin Oncol Educ Book. 2018;38:862-72.

18. Shanafelt TD, Gradishar WJ, Kosty M, Satele D, Chew H, Horn $\mathrm{L}$, et al. Burnout and career satisfaction among US oncologists. J Clin Oncol. 2014;32:678-86.
19. Ma S, Huang Y, Yang Y, Ma Y, Zhou T, Zhao H, et al. Prevalence of burnout and career satisfaction among oncologists in China: a national survey. Oncologist. 2019;24:e480-9.

20. Yeob KE, Kim SY, Park BR, Shin DW, Yang HK, Park K, et al. Burnout among oncologists in the Republic of Korea: a nationwide survey. Curr Probl Cancer. 2020;44:100535.

21. Rath KS, Huffman LB, Phillips GS, Carpenter KM, Fowler JM. Burnout and associated factors among members of the Society of Gynecologic Oncology. Am J Obstet Gynecol. 2015;213:824.

22. Dyrbye LN, Shanafelt TD, Balch CM, Satele D, Sloan J, Freischlag J. Relationship between work-home conflicts and burnout among American surgeons: a comparison by sex. Arch Surg. 2011;146:211-7.

23. Stamm BH. The concise ProQOL manual. Pocatello, ID: ProQOL; 2010.

24. Newell JM, MacNeil GA. A comparative analysis of burnout and professional quality of life in clinical mental health providers and health care administrators. J Workplace Behav Health. 2011;26:25-43.

25. Raphael MJ, Fundytus A, Hopman WM, Vanderpuye V, Seruga B, Lopes $G$, et al. Medical oncology job satisfaction: results of a global survey. Semin Oncol. 2019;46:73-82.

26. Butow P, Cockburn J, Girgis A, Bowman D, Schofield P, D'Este $\mathrm{C}$, et al. Increasing oncologists' skills in eliciting and responding to emotional cues: evaluation of a communication skills training program. Psychooncology. 2008;17:209-18.

27. Bragard I, Etienne AM, Merckaert I, Libert Y, Razavi D. Efficacy of a communication and stress management training on medical residents' self-efficacy, stress to communicate and burnout: a randomized controlled study. J Health Psychol. 2010;15:1075-81.

28. Gunasingam N, Burns K, Edwards J, Dinh M, Walton M. Reducing stress and burnout in junior doctors: the impact of debriefing sessions. Postgrad Med J. 2015;91:182-7.

29. Bretland RJ, Thorsteinsson EB. Reducing workplace burnout: the relative benefits of cardiovascular and resistance exercise. PeerJ. 2015;3:e891.

30. Jang I, Kim Y, Kim K. Professionalism and professional quality of life for oncology nurses. J Clin Nurs. 2016;25:2835-45.

31. Panagioti M, Panagopoulou E, Bower P, Lewith G, Kontopantelis E, Chew-Graham C, et al. Controlled interventions to reduce burnout in physicians: a systematic review and metaanalysis. JAMA Intern Med. 2017;177:195-205.

32. Unger JP. Physicians' burnout (and that of psychologists, nurses, magistrates, researchers, and professors) for a control program. Int J Health Serv. 2020;50:73-81.

33. Doulougeri K, Georganta K, Montgomery A. "Diagnosing" burnout among healthcare professionals: can we find consensus? Cogent Med. 2016;3:1.

34. Shanafelt TD, Hasan O, Dyrbye LN, Sinsky C, Satele D, Sloan $\mathrm{J}$, et al. Changes in burnout and satisfaction with work-life balance in physicians and the general US working population between 2011 and 2014. Mayo Clin Proc. 2015;90:1600-13. 